\title{
Pulmonary Embolism in a Young Immunocompetent Adult Infected with Cytomegalovirus. Are Novel Oral Anticoagulants an Efficient Alternative?
}

\author{
IOANNIS BOUNTOURIS ${ }^{1 *}$, DEMETRIOS MORIS ${ }^{2 *}$, DIAMANTIS I. TSILIMIGRAS ${ }^{3}$, GEORGE LAOUTARIS ${ }^{4}$, \\ GEORGIA KRITIKOU ${ }^{1}$, VIKTORIA-VARVARA PALLA ${ }^{5}$ and GEORGIOS KARAOLANIS ${ }^{3}$ \\ ${ }^{1}$ Department of Vascular Surgery, 251 General Hospital of Hellenic Air Force, Athens, Greece; \\ ${ }^{2}$ Department of Surgery, Division of Surgical Oncology, \\ The Ohio State University Wexner Medical Center, Columbus, OH, U.S.A.; \\ ${ }^{3} 1$ st Department of Surgery, Vascular Surgery Unit, Laikon General Hospital, \\ Medical School of Athens, Athens, Greece; \\ ${ }^{4} 1$ st Department of Internal Medicine, 251 General Hospital of Hellenic Air Force, Athens, Greece; \\ ${ }^{5}$ Department of Obstetrics and Gynecology, Alexandra General Hospital, Athens, Greece
}

\begin{abstract}
Background/Aim: Cytomegalovirus (CMV) infection is a common disease especially in young adults. Thromboembolism like deep vein thrombosis and pulmonary embolism is increased among patients with CMV infection. Most cases represent immunocompromised patients usually treated with low molecular weight heparin. Case Report: Herein, we describe a 25-year-old immunocompetent male who presented at the emergency department with sudden onset of chest pain. One month prior to admission, he had developed persistent fever and cough and the diagnosis of CMV infection had been established. After extensive workup, the diagnosis of pulmonary embolism after CMV infection was set and he was treated with rivaroxaban. During the next six months the patient continued on the same anticoagulant therapy with no other episode of pulmonary embolism at 1year follow-up. Conclusion: To our knowledge, this is the first case of CMV-associated pulmonary embolism treated with novel oral anticoagulants (NOACs). NOACs, such as rivaroxaban, seem to be safe and may represent an attractive alternative with promising results in this particular group of
\end{abstract}

This article is freely accessible online.

*These Authors contributed equally to this study.

Correspondence to: Dr. Georgios Karaolanis, "Laiko" Hospital, 17 St. Thomas Str., Athens 11527, Greece. Tel: +30 6972200011, Fax: +30 213206176, e-mail: drgikaraolanis@gmail.com

Key Words: Pulmonary, embolism, immunocompetent, CMV, NOACs. patients. Studies incorporating a greater cohort of patients are needed in order to draw safe conclusions regarding the relationship between NOACs and CMV infection.

Cytomegalovirus (CMV) infection is usually asymptomatic or resembles infectious mononucleosis syndrome, which is characterized by fever, malaise, muscular-skeletal pain, lymphadenopathy and atypical lymphocytosis. Of note, the reports of thromboembolic events such as pulmonary embolism (PE) associated to acute CMV infection are increasing (1). Venous thromboembolism has been reported in association with CMV infection both in immunocompromised and immunocompetent patients. In the latter population, it is yet not determined whether CMV alone provokes venous thromboembolism (VTE) or other predisposing conditions are involved $(2,3)$. The correct assessment of the patient's clinical status, in association with the procoagulant risk factors could be useful to reach the diagnosis of PE. We present and analyze the first -to our knowledge- case of CMV related PE in an immunocompetent young patient, treated with novel oral anticoagulants (NOACs).

\section{Case Report}

A 25-year-old male presented to the emergency room with sudden onset of chest pain. One month prior to the admission, he had developed persistent fever and cough, and following detailed assessment, diagnosis of CMV infection was established. There was no history of smoking, alcohol intake or other comorbidities. His temperature was $36.9^{\circ} \mathrm{C}$, blood pressure was $125 / 55$, heart rate $125 / \mathrm{min}$, respiratory rate $22 /$ min with oxygen saturation $100 \%$ at 21 of oxygen. 


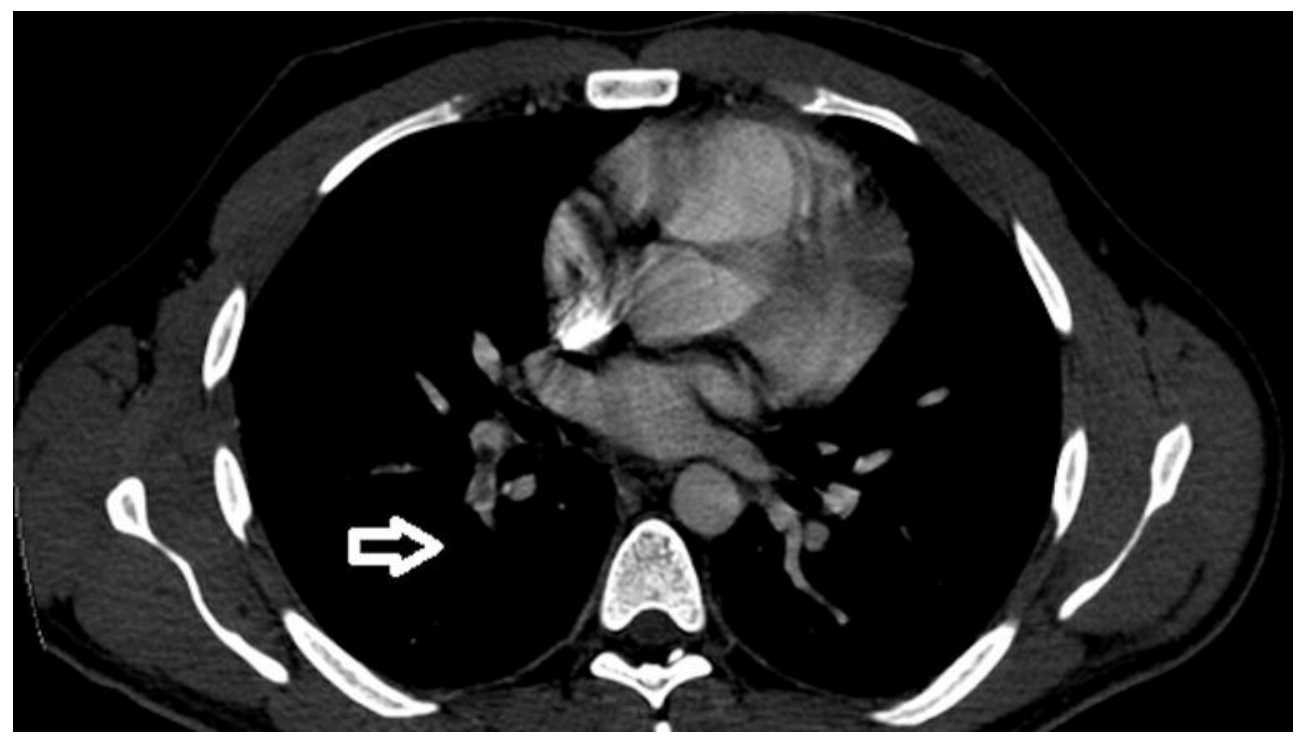

Figure 1. CT shows pulmonary embolism in a branch of the right pulmonary artery (white arrow).

Blood gas test revealed normal values whereas heart auscultation revealed a normal rhythm with no murmurs.

Laboratory data on admission revealed a WBC count of $7,200 \mathrm{cell} / \mathrm{ml}$ with $60 \%$ atypical lymphocytes. Platelet count was 186.000 cells $/ \mathrm{ml}$, aspartate aminotransferase (AST) was $60 \mathrm{U} / 1$, alanine aminotransferase (ALT) $175 \mathrm{U} / 1$, alkaline phosphatase (ALP) $98 \mathrm{U} / 1$ and D-Dimers $4,5 \mathrm{mg} / \mathrm{dl}$. A CT of the lungs with intravenous contrast (Figure 1), showed a filling defect in the right pulmonary artery. Moreover, color Doppler of the lower limb veins revealed a fresh thrombus in the posterior tibial vein of the right foot (Figure 2). A hypercoagulability workup performed before the introduction of heparin therapy detected normal plasma antithrombin III, Protein $\mathrm{C}$ and $\mathrm{S}$ activity. There was no $\mathrm{V}$ Leiden factor or prothrombin mutation. Homocysteine levels were $11,35 \mathrm{mg} / \mathrm{dl}$.

Treatment with new oral anticoagulants (rivaroxaban) was immediately initiated with $15 \mathrm{mg}$ twice a day for 21 days and thereafter $20 \mathrm{mg}$ once a day. Nine days after the admission, a control CT of the lungs and abdomen showed a slight reduction in the areas of consolidation. During the next six months the patient continued on anticoagulant therapy with no other episode of pulmonary embolism at 1-year follow-up.

\section{Discussion}

The association of CMV infection with vascular thrombosis was first described in immunocompromised patients. However, CMV-associated thrombosis has been reported in immunocompetent patients as well (4-7). Certain theories suggest that CMV triggers thrombosis by infecting endothelial

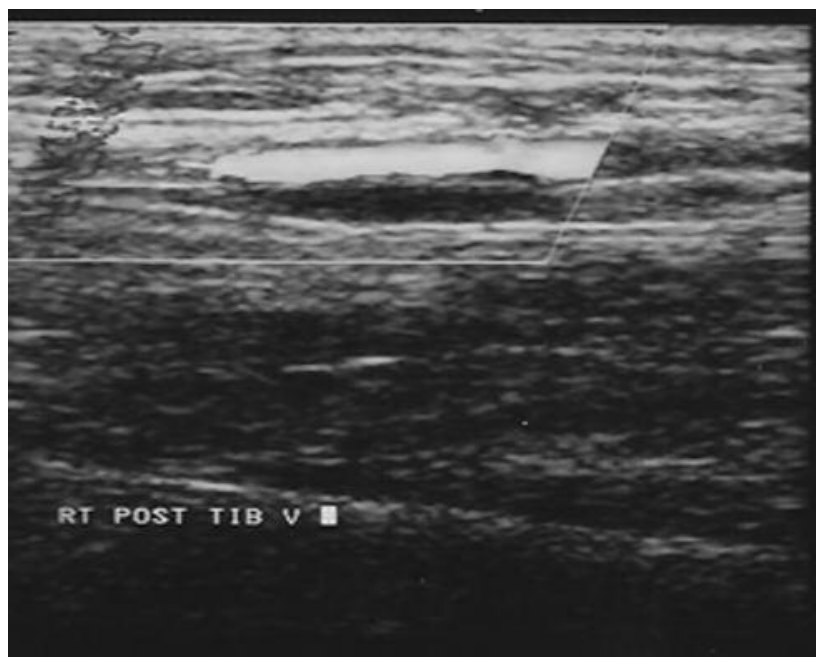

Figure 2. Color Doppler with posterior tibial vein thrombosis.

cells and enhancing platelet adhesion to the infected cells, by activating factor $\mathrm{X}$ and increasing circulatory levels of factor VIII (8) as well as through the gene IE84 (9). However, the most accepted theory supported by several in vitro studies suggests that CMV transiently induces production of antiphospholipid antibodies (10). Recently, various studies (2, 3, 11-13) evaluated the incidence of CMV associated thrombosis. These studies revealed that acute CMV infection may increase the likelihood of thrombosis only during active infection. In the 
literature, administration of intravenous heparin, low-molecular weight heparin and warfarin were selected as a treatment of choice in treating PE. A large retrospective study of 1007 VTE patients demonstrated an incidence of $0.1 \%$ synchronous acute CMV infection. These patients with coexistent VTE and acute CMV infection were typically younger and exhibited a female predominance (3). Hereditary thrombophilia was identified in $90 \%$ of these patients. Oral contraceptives and pregnancy were not additive risk factors (3).

The most recent update of the American College of Chest Physicians (ACCP) Guidelines on Antithrombotic Therapy from 2012 (14) recommends rivaroxaban as an alternative option for PE treatment to warfarin. Rivaroxaban was shown to be noninferior to warfarin in both the DVT and PE studies $(15,16)$, whereas the risk of major bleeding was statistically lower only in the PE study (16). Based on these findings and according to the younger age of the patient, NOACs were selected as a treatment of choice for 6 months. This is the unique case in which the patient was immunocompetent without thrombosis risk factors and the use of NOACs was effective in the progress of the disease. Due to the mild symptoms of primary infection, it was decided that the patient should not receive any antiviral drugs. This approach was confirmed by a recent review suggesting that antiviral therapy should be considered for patients presenting with severe VTE, VTE with a negative outcome despite anticoagulation, severe organ involvement, or for patients managed in the intensive care unit (17).

\section{Conclusion}

Our case highlights that physicians should be alert for symptoms and signs of thrombosis in patients with acute CMV infection and vice versa. NOACs, such as rivaroxaban, seem to be safe and may represent an attractive alternative with promising results in this particular group of patients. Studies incorporating a greater cohort of patients are needed in order to draw safe conclusions regarding the relationship between NOACs and CMV infection.

\section{Conflicts of Interest}

None.

\section{Acknowledgements}

None.

\section{References}

1 Rafailidis PI, Mourtzoukou EG, Varbobitis IC and Falagas ME: Severe cytomegalovirus infection in apparently immunocompetent patients: a systematic review. Virol J 5: 47, 2008.

2 Paran Y, Shalev V, Steinvil A, Justo D, Zimmerman O, Finn T, Berliner S, Zeltser D, Weitzman D, Raz R and Chodick G:
Thrombosis following acute cytomegalovirus infection: a community prospective study. Ann Hematol 92(7): 969-974, 2013.

3 Yildiz $\mathrm{H}$, Zech $\mathrm{F}$ and Hainaut P: Venous thromboembolism associated with acute cytomegalovirus infection: epidemiology and predisposing conditions. Acta Clin Belg 71(4): 231-234, 2016.

4 Bauduer F, Blanc A and Cordon B: Deep vein thrombosis and acute cytomegalovirus infection: case report and review of the literature. Blood Coagul Fibrinolysis 14(5): 489-491, 2003.

5 Bensaid B, Pavic M, Estival JL, Rabar D, Dupin M and Combemale P: [Deep venous thrombosis revealed by skin rash during initial cytomegalovirus infection]. Ann Dermatol Venereol 134(10 Pt 1): 779-780, 2007.

6 Fridlender ZG, Khamaisi M and Leitersdorf E: Association between cytomegalovirus infection and venous thromboembolism. Am J Med Sci 334(2): 111-114, 2007.

7 Paran Y, Halutz O, Swartzon M, Schein Y, Yeshurun D and Justo D: Venous thromboembolism and cytomegalovirus infection in immunocompetent adults. Isr Med Assoc J 9(10): 757-758, 2007.

8 Squizzato A, Gerdes VE and Buller HR: Effects of human cytomegalovirus infection on the coagulation system. Thromb Haemost 93(3): 403-410, 2005.

9 Chiu B, Viira E, Tucker W and Fong IW: Chlamydia pneumoniae, cytomegalovirus, and herpes simplex virus in atherosclerosis of the carotid artery. Circulation 96(7): 2144-2148, 1997.

10 Delbos V, Abgueguen P, Chennebault JM, Fanello S and Pichard E: Acute cytomegalovirus infection and venous thrombosis: role of antiphospholipid antibodies. J Infect 54(1): e47-50, 2007.

11 Atzmony L, Halutz O, Avidor B, Finn T, Zimmerman O, Steinvil A, Zeltser D, Giladi M and Justo D: Incidence of cytomegalovirusassociated thrombosis and its risk factors: a case-control study. Thromb Res 126(6): e439-443, 2010.

12 Schimanski S, Linnemann B, Luxembourg B, Seifried E, Jilg W, Lindhoff-Last E and Schambeck CM: Cytomegalovirus infection is associated with venous thromboembolism of immunocompetent adults - a case-control study. Ann Hematol 91(4): 597-604, 2012.

13 Tichelaar VY, Sprenger HG, Makelburg AB, Niesters BG, KluinNelemans HC and Lijfering WM: Active cytomegalovirus infection in patients with acute venous thrombosis: a casecontrol study. Am J Hematol 86(6): 510-512, 2011.

14 Bates SM, Jaeschke R, Stevens SM, Goodacre S, Wells PS, Stevenson MD, Kearon C, Schunemann HJ, Crowther M, Pauker SG, Makdissi R and Guyatt GH: Diagnosis of DVT: Antithrombotic Therapy and Prevention of Thrombosis, 9th ed: American College of Chest Physicians Evidence-Based Clinical Practice Guidelines. Chest 141(2 Suppl): e351S-e418S, 2012.

15 Nunnelee JD: Review of an article: oral rivaroxaban for symptomatic venous thromboembolism. The EINSTEIN Investigators et al. N Engl J Med 2010; 363(26): 2499-2510. J Vasc Nurs 29(2): 89, 2011.

16 Romualdi E, Donadini MP and Ageno W: Oral rivaroxaban after symptomatic venous thromboembolism: the continued treatment study (EINSTEIN-extension study). Expert Rev Cardiovasc Ther 9(7): 841-844, 2011.

17 Deconinck L, Flateau C, Pichenot M, Morell-Dubois S, Maillard H, Hatron PY, Guery B and Faure K: Antiviral therapy of primary cytomegalovirus infection with vascular thrombosis in immunocompetent adults. Med Mal Infect 46(2): 87-92, 2016.

Received August 31, 2017

Revised September 18, 2017

Accepted September 19, 2017 